\title{
Study of Lipid Abnormalities in Type 2 Diabetes Mellitus Patients with Nephropathy in Eastern India
}

\author{
Sonalika Behera1, Andrew Abel Lamare², Bijan Patnaik', Roma Rattan², Sidhartha Das' \\ ${ }^{1}$ Department of Medicine, Sriram Chandra Bhanja Medical College, Cuttack.odisha, India \\ ${ }^{2}$ Department of Biochemistry, Sriram Chandra Bhanja Medical College, Cuttack.odisha, India \\ Email:drsonalika10@gmail.com
}

How to cite this paper: Behera, S., Lamare, A.A., Patnaik, B., Rattan, R. and Das, S. (2020) Study of Lipid Abnormalities in Type 2 Diabetes Mellitus Patients with Nephropathy in Eastern India. Journal of Diabetes Mellitus, 10, 16-25.

https://doi.org/10.4236/jdm.2020.101002

Received: January 16, 2020

Accepted: February 25, 2020

Published: February 28, 2020

Copyright $\odot 2020$ by author(s) and Scientific Research Publishing Inc. This work is licensed under the Creative Commons Attribution-NonCommercial International License (CC BY-NC 4.0). http://creativecommons.org/licenses/by-nc/4.0/ (c) (i) (s) Open Access

\begin{abstract}
Background: Diabetic nephropathy is one of the major complications of diabetes. Nephropathy patients must be evaluated for dyslipidemia as it is an established risk factor for cardiovascular events. We compared the degree of dyslipidemia among type 2 diabetes mellitus (T2DM) subjects with or without nephropathy and analyzed the factors associated with nephropathy among them. Methods: In this retrospective study, T2DM patients with overt nephropathy were enrolled in the study group $(n=50)$; without nephropathy were enrolled in the control group $(n=50)$. Both groups were matched for age duration of diabetes. After taking informed consent anthropometrical clinical examinations were done. Biochemical investigations (Total cholesterol, TG, HDL, LDL, VLDL, sdLDL-C, $S$. urea, $S$. creatinine were done in SCB MCH, Biochemistry department. Urine microalbumin per gm of creatinine was done. TG/HDL-C ratio, a surrogate marker for small, dense, LDL particles (sdLDL), and estimated glomerular filtration rate (eGFR) were calculated using equations. Results were analyzed statistically using SPSS version 20. Results: Mean Total cholesterol, TG, LDL, sdLDL are significantly high in nephropathy patients with $\mathrm{p}$ values $0.026,0.012,0.014,0.04$ respectively. Estimated GFR has a significant positive correlation with TCHOL $(\mathrm{r}=-0.850, \mathrm{p}=$ $0.01)$, TG $(\mathrm{r}=-0.14, \mathrm{p}=0.008)$, LDL $(\mathrm{r}=-0.62 \mathrm{p}=0.037)$. Estimated GFR has a significant negative correlation with $S$. urea $(\mathrm{r}=-0.587, \mathrm{p} \leq 0.01), S$. creatinine $(\mathrm{r}=-0.59, \mathrm{p} \leq 0.01)$, UACR $(\mathrm{r}=-0.47, \mathrm{p} \leq 0.01)$. Dyslipidema sdLDL is significantly more in nephropathy group in comparison to diabetic group with p values $0.033,0.045$ respectively. Conclusion: Our study shows that dyslipidemia was highly prevalent among subjects with nephropathy. So cardiovascular risks can be averted by regular screening for dyslipidemia in diabetic nephropathy patients.
\end{abstract}




\section{Keywords}

Dyslipidemia, Diabetic Nephropathy, Insulin Resistance, sdLDL, Atherogenic Dyslipidemia

\section{Introduction}

Austin colleagues first explained Atherogenic Dyslipidemia (AD) as a clinical condition [1] characterized by elevated levels of serum triglyceride (TG) levels small-dense low-density lipoprotein (sdLDL) particles with low levels of high-density lipoprotein cholesterol (HDL-C) [2]. Dyslipidemia of metabolic syndrome is considered as an important CVD (Cardiovascular disease) risk factor in these patients. Long-standing diabetes causes dysfunction of lipoprotein lipase as a result increase in further TG level. TG level causes accumulation of large TG-rich very low density lipoprotein particles, which in turn generate sdLDL particles [3]. Hypertriglyceridaemia is the common dyslipidemia seen in uncontrolled diabetic state, insulin resistant stage presence of nephropathy in Type 2 diabetics. Diabetic nephropathy is one of the major complications of diabetes, characterized by proteinuria renal insufficiency, an established risk factor for cardiovascular events as well as mortality [4] [5]. Dyslipidemia leads to progressive loss of renal function among diabetic patients [6] by causing damage to vascular, mesangial, tubular cells of kidneys [7]. Dyslipidemia and nephropathy act synergistically in worsening the clinical condition, increasing the risk of renal or cardiovascular consequences among diabetic patients [8] [9]. In recent years in Indian population AD and CVD are increasing compared to western population, which may be due to adverse life style changes such as physical inactivity, diet deficient in PUFA a higher genetic predisposition [10]. We conducted a retrospective analysis comparing the extent of dyslipidemia among diabetic nephropathy patients, also evaluated the risk factors associated with nephropathy among them.

\section{Study}

This study was a hospital based observational study.

\subsection{Materials}

Consecutive Patients of Type 2 Diabetes Mellitus (DM) with or without microalbuminuria attending SCB MEDICAL COLLEGE HOSPITAL Medical OPDs inone year. Patients were subjected to blood and urine investigations patients were divided in to two groups. Group 1 Type 2 Diabetes Mellitus without microalbuminuria as indicated by $<30 \mathrm{mg}$ of albumin per gram of creatinine on spot urine sample and in the three most recent lab reports. Type $2 \mathrm{DM}$ was diagnosed according to WHO guidelines: 1) Random Plasma Glucose more than $200 \mathrm{mg} \%$ with classical symptoms of hyperglycaemias. Or 2) Fasting Plasma Glucose more 
than $126 \mathrm{mg} \%$ or 3) 2-hour Plasma Glucose more than $200 \mathrm{mg} \%$ by oral glucose tolerance test. or 4) $\mathrm{HbAlc}$ more than $6.5 \%$. Group 2 included subjects with nephropathy. Diabetic nephropathy patients were defined as on the basis of Kidney Disease Improving Global Outcome (KDIGO) classification of chronic kidney disease and GFR calculated using COCKRAUFT'S Formulae. Cockrauft's formulae: $\mathrm{C}_{\mathrm{Cr}}=\left\{((140-\right.$ age $) \times$ weight $\left.) /\left(72 \times \mathrm{S}_{\mathrm{Cr}}\right)\right\} \times 0.85$ (if female). Exclusion criteria: The subjects who did not able to underst sign the study specific informed consent were excluded from study.

\subsection{Methods}

After getting consents anthropometric details such as height, weight, BMI detailed clinical examinations were done. Details regarding their medications, diet life style habits were also collected. Fasting post prandial venous blood was collected and processed for biochemical tests. Plasma glucose levels were estimated by GOD-POD (Glucose oxidase peroxidase) method adapted to autoanalyzer (Toshiba 120FR, JAPAN). Serum total cholesterol is estimated by CHOD-PAP (cholesterol oxidase-peroxidase) method adapted to autoanalyzer (Toshiba120FR, AGGAPE, JAPAN). Estimation of Serum Triglyceride by Glycerol-3-Phosphate-oxidase/Peroxidase method (GPO-TOPS) adapted to autoanalyzer (Toshiba 120FR. AGGAPE, JAPAN). Estimation of serum HDL cholesterol by selective inhibition method adapted to autoanalyzer (Toshiba 120FR, JAPAN). Serum LDL level was estimated by Friedewald formula. FRIEDEWALD FORMULA, LDL $=$ Total Cholesterol-[HDL + (Triglyceride/5) $]$ Results were expressed in mg/dL. Serum VLDL level was estimated by Friedewald formula. FRIEDEWALD FORMULA, VLDL $=$ Triglyceride/5. Results were expressed in $\mathrm{mg} / \mathrm{dl}$. 1) Dyslipidemia: total cholesterol $\geq 200 \mathrm{mg} / \mathrm{dL}$ or triglycerides (TG) $\geq$ $150 \mathrm{mg} / \mathrm{dL}$ or high density lipoprotein cholesterol (HDL-C) $\leq 35 \mathrm{mg} / \mathrm{dL}$ (for men) $\leq 40 \mathrm{mg} / \mathrm{dL}$ (for women) or low density lipoprotein cholesterol $\geq 100$ $\mathrm{mg} / \mathrm{dL}$ or a combination of these conditions 2) sdLDL: TG/HDL-C ratio $>3,3$ ) Atherogenic dyslipidemia: TG $\geq 150 \mathrm{mg} / \mathrm{dL}+\mathrm{HDL}-\mathrm{C} \leq 35 \mathrm{mg} / \mathrm{dL}$ (for men) $\leq 40$ $\mathrm{mg} / \mathrm{dL}$ (for women) + sdLDL ratio $>3$. Serum urea level was estimated by (GLDH/KINETIC) method adapted to autoanalyzer (Toshiba 120FR, JAPAN). Serum creatinine was estimated by enzymatic method adapted to autoanalyzer (Toshiba 120FR). Glycated haemoglobin was done by High-performance liquid chromatography. First-morning urine samples were collected under sterile conditions. The same specimen was used for urinary the measurement of albumin-creatinine ratio, ACR $(\mu \mathrm{g} / \mathrm{mg})$. ACR $<30 \mu \mathrm{g} / \mathrm{mg}$ was defined as normoalbuminuria, $30-300 \mu \mathrm{g} / \mathrm{mg}$ as microalbuminuria, ACR $>300 \mu \mathrm{g} / \mathrm{mg}$ as macroalbuminuria. Urine microalbumin were done in standard kits adapted to semi auto analyser (Toshiba 120 FR, AGAPPE). Urine Albumin: Creatinine Ratio (UACR) calculated by the formula, which has been approved by National Kidney Disease Education Program. UACR in $\mathrm{mg} / \mathrm{g}=$ Urine albumin $(\mathrm{mg} / \mathrm{dL}) /$ Urine creatinine $(\mathrm{g} / \mathrm{dL})$. 


\subsection{Statistical Analysis}

Statistical analysis was done using SPSS package version 20.0 (SPSS Inc., Chicago, IL, USA). Quantitaive variables were described as mean \pm standard deviation unless otherwise indicated. Qualitative variables were mentioned as percentages. Pearson's correlation co-efficient, ANOVA with post Hoc analysis, logistic regression analysis, multivariate analysis were used.

\section{Result}

Table 1 shows the male:female ratio was 70:22, 61:28 respectively for these groups 1 and 2. Mean HBA1C is not significant in both groups. Both groups are on regular treatment for diabetes. Both groups did not take any lipid lowering drugs. Mean total cholesterol, TG, LDL levels are high in nephropathy group with $\mathrm{p}$ values $0.026,0.012,0.014$ respectively. sdLDL is calculated TG/HDL ratio. Mean sdLDL are hign in nephropathy group. LDL/HDL level in both groups are not significant. Serum urea was higher among nephropathy. Mean GFR (19.21 \pm 9.51 ) is lower in nephropathy group with $\mathrm{p}$ value $<0.001$. Mean UACR levels are significant in nephropathy group with $\mathrm{p}$ values $<0.001$.

Table 2 shows shows eGFR as dependent variable has significant relation with S.urea $(\mathrm{p}<0.01)$, S.creatinine $(\mathrm{p}<0.01)$, UACR $(\mathrm{p}<0.01)$, T.cholesterol $(\mathrm{p}=$ $0.01)$, TG $(\mathrm{p}=0.008)$ and LDL $(\mathrm{p}=0.037)$ with $\mathrm{p}$ value $<0.05$. eGFR has no significant relation with HDL, sdLDL, LDL/HDL.

Table 3 shows eGFR has significant correlation with TCHOL $(\mathrm{r}=-0.850, \mathrm{p}=$ $0.01)$, TG $(r=-0.14, p=0.008)$, LDL $(r=-0.62, p=0.037)$. eGFR has significant negative correlation with s.urea $(\mathrm{r}=-0.587, \mathrm{p} \leq 0.01)$, s.creatinine $(\mathrm{r}=-0.59$, $\mathrm{p} \leq 0.01)$, UACR $(\mathrm{r}=-0.47, \mathrm{p} \leq 0.01)$. Surea has positive correlation with TCHOL, TG, LDL ( $\mathrm{p}$ values mentioned in above table). $S$. creatinine has no

Table 1. Comparison of anthropometric measurements biochemical estimations between Diabetes subjects with or without nephropathy.

\begin{tabular}{cccc}
\hline Parameters & $\begin{array}{c}\text { Diabetes mellitus subjects } \\
\text { without Nephropathy }\end{array}$ & $\begin{array}{c}\text { Diabetic subjects } \\
\text { With nephropathy }\end{array}$ & P VALUE \\
\hline Age $(\mathrm{yrs})$ & $51.02 \pm 12.12$ & $50.10 \pm 10.92$ & 0.57 \\
BMI $\left(\mathrm{kg} / \mathrm{m}^{2}\right)$ & $21.25 \pm 2.32$ & $22.9 \pm 2.59$ & 0.21 \\
HBA1C $(\%)$ & $7.93 \pm 0.81$ & $8.05 \pm 0.83$ & 0.484 \\
T.chol $(\mathrm{mg} / \mathrm{dl})$ & $142.8 \pm 48.99$ & $163.24 \pm 41.25$ & 0.026 \\
TG (mg/dl) & $132.3 \pm 58.04$ & $177.02 \pm 25.11$ & 0.012 \\
HDL $(\mathrm{mg} / \mathrm{dl})$ & $56.24 \pm 25.91$ & $62.12 \pm 21.77$ & 0.22 \\
LDL $(\mathrm{mg} / \mathrm{dl})$ & $59.68 \pm 31.74$ & $25.90 \pm 8.69$ & 0.014 \\
VLDL $(\mathrm{mg} / \mathrm{dl})$ & $28.06 \pm 11.52$ & $2.89 \pm 0.22$ & 0.293 \\
Sd LDL & $2.28 \pm 1.96$ & $1.20 \pm 0.62$ & 0.04 \\
LDL/HDL & $1.21 \pm 0.82$ & $19.21 \pm 9.51$ & 0.69
\end{tabular}


Table 2. Results of multiple linear regression analysis with estimated glomerular filtration rate (eGFR) as dependent variable.

\begin{tabular}{ccc}
\hline Independent variable & $P$ value & $R$ square for the model \\
\hline BMI & 0.46 & 0.221 \\
HBA1C & 0.613 & $<0.01$ \\
UREA & $<0.01$ \\
CREATININE & $<0.01(\mathrm{r}=-0.47)$ \\
UACR & 0.01 \\
TCHOL & 0.008 \\
TG & 0.70 \\
HDL & 0.037 \\
LDL & 0.44 \\
SdLDL & 0.9 \\
LDL/HDL &
\end{tabular}

Table 3. Correlation table.

\begin{tabular}{cccccccc}
\hline & TCHOL & TG & HDL & LDL & VLDL & sdLDL & LDL/HDL \\
\hline \multirow{2}{*}{ S.UREA } & $\mathrm{r}=0.240$ & $\mathrm{r}=0.268$ & $\mathrm{r}=0.02$ & $\mathrm{r}=0.225$ & $\mathrm{r}=0.06$ & $\mathrm{r}=0.10$ & $\mathrm{r}=0.13$ \\
& $\mathrm{p}=0.016$ & $\mathrm{p}=0.007$ & $\mathrm{p}=0.83$ & $\mathrm{p}=0.025$ & $\mathrm{p}=0.95$ & $\mathrm{p}=0.28$ & $\mathrm{p}=0.19$ \\
& & & & & & & \\
S.CREATININE & $\mathrm{r}=0.174$ & $\mathrm{r}=0.213$ & $\mathrm{r}=0.055$ & $\mathrm{r}=0.138$ & $\mathrm{r}=0.117$ & $\mathrm{r}=0.020$ & $\mathrm{r}=0.018$ \\
& $\mathrm{p}=0.084$ & $\mathrm{p}=0.033$ & $\mathrm{p}=0.584$ & $\mathrm{p}=0.170$ & $\mathrm{p}=0.246$ & $\mathrm{p}=0.843$ & $\mathrm{p}=0.857$ \\
& & & & & & & \\
UACR & $\mathrm{r}=0.138$ & $\mathrm{r}=0.91$ & $\mathrm{r}=0.056$ & $\mathrm{r}=0.81$ & $\mathrm{r}=0.53$ & $\mathrm{r}=-0.038$ & $\mathrm{r}=-0.004$ \\
& $\mathrm{p}=0.171$ & $\mathrm{p}=0.036$ & $\mathrm{p}=0.578$ & $\mathrm{p}=0.04$ & $\mathrm{p}=0.019$ & $\mathrm{p}=0.707$ & $\mathrm{p}=0.968$ \\
& & & & & & & \\
GFR & $\mathrm{r}=-0.850$ & $\mathrm{r}=-0.14 \mathrm{r}=-0.038$ & $\mathrm{r}=-0.62$ & $\mathrm{r}=0.172$ & $\mathrm{r}=0.078$ & $\mathrm{r}=0.013$ \\
& $\mathrm{p}=0.01$ & $\mathrm{p}=0.008$ & $\mathrm{p}=0.705$ & $\mathrm{p}=0.037$ & $\mathrm{p}=0.45$ & $\mathrm{p}=0.44$ & $\mathrm{p}=0.902$ \\
\hline
\end{tabular}

significant correlation with lipid profile. UACR has positive correlation with $\mathrm{TG}(\mathrm{r}=0.91, \mathrm{p}=0.036) \operatorname{LDL}(\mathrm{r}=0.81, \mathrm{p}=0.04)$, VLDL $(\mathrm{r}=-0.53, \mathrm{p}=0.019)$.

Table 4 reveals the percentage of subjects with dyslipidemia $54 \%$ in diabetic without nephropathy group and $60 \%$ in nephropathy group. There is significant difference between these two groups with p value 0.033 . The percentage of subjects with sdLDL are $26 \%$ in DM $30 \%$ in nephropathy group with p value 0.045 . The percentage of subjects with atherogenic dyslipidemia was $14.13 \%$ $(n=13)$ among controls $14.61 \%(n=13)$ among nephropathy subjects. Atherogenic dyslipidemia in this study is defined as TG $\geq 150 \mathrm{mg} / \mathrm{dL}+\mathrm{HDL}-\mathrm{C} \leq$ $35 \mathrm{mg} / \mathrm{dL}$ (for men) $\leq 40 \mathrm{mg} / \mathrm{dL}$ (for women) + TG/HDL-C ratio $\geq 3$. Atherogenic dyslipidemia is $8 \%$ in diabetic and $4 \%$ in nephropathy group. No significant difference between these two groups. Comparison of occurence of dyslipidemia in between diabetic subjects without nephropathy and with nephropathy shown in Figure 1. 
Table 4. Comparison of the occurrence of dyslipidemia between subjects with without nephropathy.

\begin{tabular}{cccc}
\hline Variables & $\begin{array}{c}\text { Diabetic subjects } \\
\text { without Nephropathy }\end{array}$ & $\begin{array}{c}\text { Diabetic subjects with } \\
\text { Nephropathy }\end{array}$ & P value \\
\hline dyslipidemia & $27(54 \%)$ & $30(60 \%)$ & 0.033 \\
sdLDL & $13(26 \%)$ & $15(30 \%)$ & 0.045 \\
LDL/HDL & $1(2 \%)$ & $2(4 \%)$ & 0.205 \\
Atherogenic dyslipidemia & $2(4 \%)$ & $4(8 \%)$ & 0.205 \\
\hline
\end{tabular}

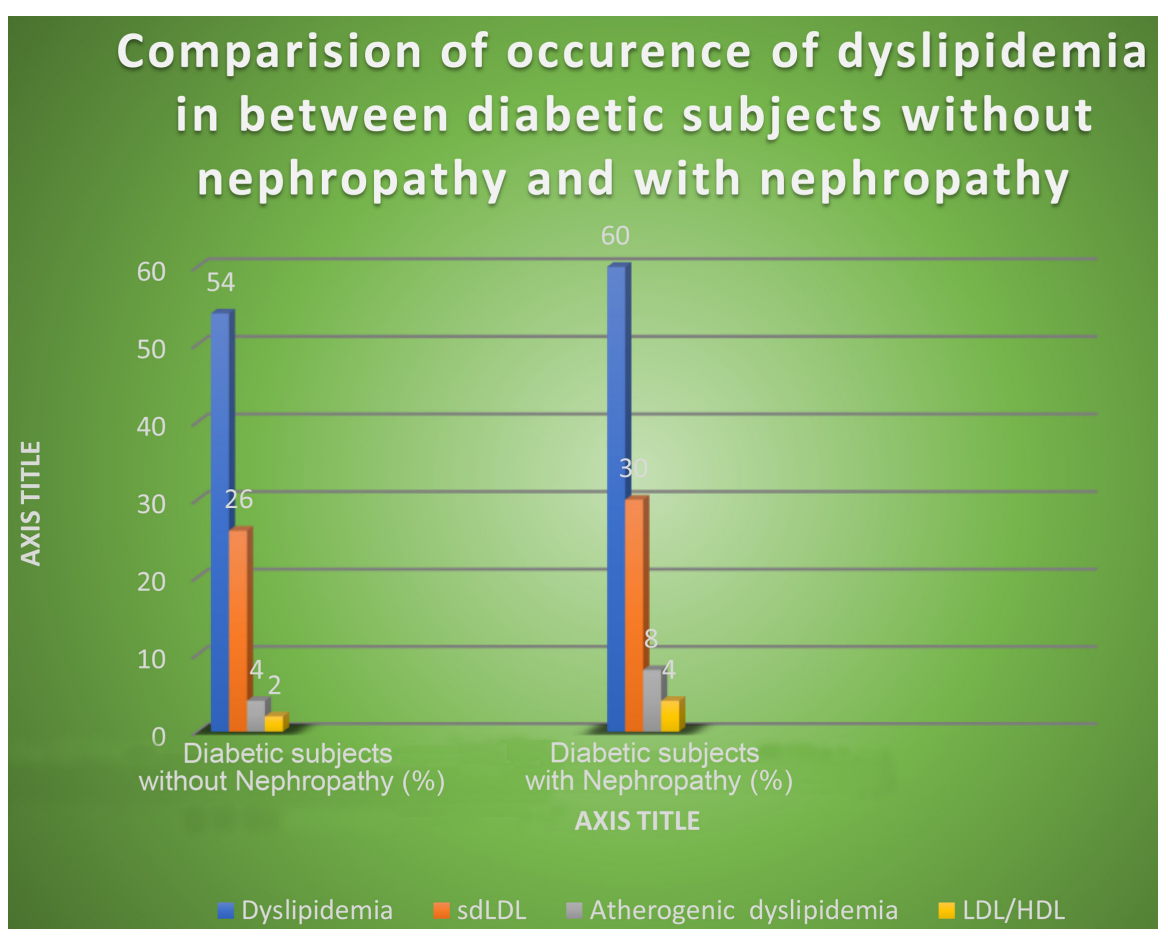

Figure 1. Comparision of occurence of dyslipidemia in between diabetic subjects without nephropathy and with nephropathy.

\section{Discussion}

Dyslipidemia is commonly present among people with nephropathy. According to Kidney Disease: Improving Global Outcomes (KDIGO) clinical practice guidelines for lipid management in chronic kidney disease, adults with recently identified kidney disease should be evaluated for dyslipidemia [11]. According to the Framingham Heart Study published in 1959, cholesterol levels were the first confirmed cardiovascular risk factor in nephropathy group [12]. Albuminuria which is the hallmark of diabetic nephropathy highlights the prognosis of diabetic nephropathy which is described in KDIGO. Diabetes Control Complications Trial (DCCT) revealed that albuminuria is associated with higher levels of TC, TG, LDL-C [13]. The results of our study show that TC, TG, LDL-C levels were significantly higher among the nephropathy patients which shown that TC, TG, HDL-C, LDL-C were significantly different between diabetic diabetic neph- 
ropathy patients [14]. In Indian subjects with diabetes, hypertriglyceridemia with increased VLDL is more common dyslipidaemia than low high density lipoprotein (HDL) cholesterol levels [3]. A study conducted even in a different ethnic population has observed results similar to the present study [15]. Another study showed that dyslipidemia associated with diabetic nephropathy is present in both type 1 and type 2 diabetes mellitus patients. Poor glycemia is a major cause of dyslipidemia. Recently, small dense low density lipoproteincholesterol (sdLDL-C) considered as one of the lipoprotein risk factors for coronary heart disease (CHD) as the best marker of carotid atherosclerosis [16] [17]. The percentage of subjects with sdLDL, indicated by TG/HDL-C ratio, was high among both groups in this study population and the percentage differed significantly between the two groups with $\mathrm{p}$ value 0.045 shown in Table 4 . In patients with poor glycemic control, levels of TG rich lipoproteins are higher. This rise is not only due to over production of VLDL but also poor peripheral clearance consequent to lesser expression of ApoB100 receptors on endothelial cell surface. In uncontrolled patients with Type-2 DM, the recycling of receptors is also slow. Glycated ApoB100 has longer interaction with its receptors so prolongs the half life of both LDL VLDL molecules (S.Das). But a study including diabetic Japanese subjects had shown that LDL particle size was significantly lower in nephropathy patients compared to subjects without nephropathy [18]. LDL/HDL also varies between diabetic and nephropathy group but in our study this is not significantly different. The correlation between lipid parameters kidney function parameters in the current study implies that dyslipidemia is associated with renal insufficiency in this population. Various prospective studies have shown that there is a significant correlation between renal outcome dyslipidemia [19]. Therapeutic intervention using statins to reduce cholesterol level has been recognized to reduce the risk for adverse cardiovascular events among subjects with kidney disease [20]. These data of previous studies have shown that TChol level was associated with a higher risk of mortality in patients with chronic renal failure [19] [20] [21]. Chen et al. [21] in a more recent large-scale study among 3303 patients with chronic kidney disease stages 3 to 5 observed that the association between TC mortality is different among patients with different levels of proteinuria. Correlation table shows TCHOL has significant negative correlation with GFR (P VALUE 0.01) shown in Table 3. As the GFR level declines T.CHOL level increases. Our study also states this same. Physicians Health Study had demonstrated that the risk for deterioration of renal function was significant among subjects with elevated cholesterol or low HDL-C, even at mildly elevated serum creatinine values [22] [23]. In our study S. creatinine has no significant correlation with lipid profile parameters [24]. Dyslipidemia of metabolic syndrome is considered as an important CVD (Cardiovascular disease) risk factor in these patients [25]. Despite being a retrospective analysis of small sample size, the study has been able to obtain useful data on the prevalence of dyslipidemia among diabetic nephropathy patients. 


\subsection{Summary}

Although many studies previously are there on prevalence of dyslipidemia in diabetes and diabetic nephropathy, they are not detailed studied on lipid parameters in diabetic nephropathy. In our study Mean Total cholesterol, TG, LDL, sdLDL are significantly high in nephropathy patients with $\mathrm{p}$ values $0.026,0.012$, 0.014, 0.04 respectively. Estimated GFR has significant positive correlation with Total Cholesterol $(\mathrm{r}=-0.850, \mathrm{p}=0.01)$, TG $(\mathrm{r}=-0.14, \mathrm{p}=0.008)$, LDL $(\mathrm{r}=$ $-0.62, p=0.037)$. Estimated GFR has significant negative correlation with S.urea $(\mathrm{r}=-0.587, \mathrm{p} \leq 0.01)$, S.creatinine $(\mathrm{r}=-0.59, \mathrm{p} \leq 0.01)$, UACR $(\mathrm{r}=-0.47, \mathrm{p} \leq$ 0.01 ). Dyslipide mia sdLDL is significantly more in nephropathy group in comparison to diabetic group with $\mathrm{p}$ values $0.033,0.045$ respectively. Our study shows that dyslipidemia was highly prevalent among subjects with nephropathy. So cardiovascular risks can be reduced by regular screening for dyslipidemia in diabetic nephropathy patients.

\subsection{General Comments}

This is a hospital based study in eastern india. Our sample size is small so larger studies should be done in different population and different ethinicity further.

\subsection{Conclusion}

Dyslipidemia is highly prevalent in diabetic patients more so in diabetic nephropathy patients in our study. The correlation between lipid parameters kidney damage has been studied showing dyslipidemia is associated with renal impairment. Cardiovascular risks can be averted by regular screening for dyslipidemia in diabetic nephropathy patients.

\section{Acknowledgements}

Sonalika Behera wrote the manuscript. Sidhartha Das, rew Lamare, Roma Rattan, Sonalika Behera, researched the data and analyzed the results. Sidhartha Das, Bijan Patnaik contributed to the discussion. Sidhartha Das reviewed, edited and reviewed the Manuscript.

\section{Conflicts of Interest}

No potential conflict of interest relevant to this article was reported.

\section{References}

[1] Austin, M.A., King, M.C., Vranizan, K.M. and Krauss, R.M. (1990) Atherogenic Lipoprotein Phenotype. A Proposed Genetic Marker for Coronary Heart Disease Risk. Circulation, 82, 495-496. https://doi.org/10.1161/01.CIR.82.2.495

[2] Reaven, G.M., Chen, Y.D., Jeppesen, J., Maheux, P. and Krauss, R.M. (1993) Insulin Resistance Hyperinsulinemia in Individuals with Small, Dense Low Density Lipoprotein Particles. Journal of Clinical Investigation, 92, 141-146.

https://doi.org/10.1172/JCI116541 
[3] Hirano, T., Naito, H., Kurokawa, M., Ebara, T., Nagano, S., Adachi, M. and Yoshino, G. (1996) High Prevalence of Small LDL Particles in Non-Insulin-Dependent Diabetic Patients with Nephropathy. Atherosclerosis, 123, 57-72. https://doi.org/10.1016/0021-9150(95)05772-2

[4] Parving, H.H., Persson, F. and Rossing, P. (2015) Microalbuminuria: A Parameter That Has Changed Diabetes Care. Diabetes Research and Clinical Practice, 107, 1-8. https://doi.org/10.1016/j.diabres.2014.10.014

[5] Go, A.S., Chertow, G.M., Fan, D., McCulloch, C.E. and Hsu, C.Y. (2004) Chronic Kidney Disease the Risks of Death, Cardiovascular Events, Hospitalization. The New England Journal of Medicine, 351, 1296-1305. https://doi.org/10.1056/NEJMoa041031

[6] Breyer, J.A., Bain, R.P., Evans, J.K., Nahman Jr., N.S., Lewis, E.J., Cooper, M., McGill, J. and Berl, T. (1996) Predictors of the Progression of Renal Insufficiency in Patients with Insulin-Dependent Diabetes Overt Diabetic Nephropathy. The Collaborative Study Group. Kidney International, 50, 1651-1658. https://doi.org/10.1038/ki.1996.481

[7] Keane, W.F. (2000) The Role of Lipids in Renal Disease: Future Challenges. Kidney International, 75, S27-S31. https://doi.org/10.1046/j.1523-1755.57.s75.3.x

[8] Trevisan, R., Dodesini, A.R. and Lepore, G. (2006) Lipids Renal Disease. Journal of the American Society of Nephrology, 17, S145-S147. https://doi.org/10.1681/ASN.2005121320

[9] Sharma, B.K., Jindal, S.K., Rana, D.S., Gupta, B. and Kumar, M. (1980) Absence of Hyperlipidaemia in Patients of Chronic Renal Failure in Cha Chigarh. Indian Journal of Medical Research, 72, 461-464.

[10] Das, B.S., Misra, S.K., Rao, D.V., Satpathy, S.R. and Bose, T.K. (1984) Serum Lipid in Chronic Renal Failure. The Journal of the Association of Physicians of India, 32, 1019-1021.

[11] Kidney Disease: Improving Global Outcomes (KDIGO) Lipid Work Group (2013) KDIGO Clinical Practice Guideline for Lipid Management in Chronic Kidney Disease. Kidney International, 3, 259-305.

[12] Dawber, T.R.K.W., Kannel, W.B., Revotskie, N., Stokes, J., Kagan, A. and Gordon, T. (1959) Some Factors Associated with the Development of Coronary Heart Disease: Six Years' Follow up Experience in the Framingham Study. American Journal of Public Health and the Nation's Health, 49, 1349-1356. https://doi.org/10.2105/AJPH.49.10.1349

[13] Jenkins, A.J., Lyons, T.J., Zheng, D., Otvos, J.D., Lackl, D.T., McGee, D., Garvey, W.T. and Klein, R.L. (2003) DCCT/EDIC Research Group. Lipoproteins in the DCCT/EDIC Cohort: Associations with Diabetic Nephropathy. Kidney International, 64, 817-828. https://doi.org/10.1046/j.1523-1755.2003.00164.x

[14] Suchitra, M.M., Sheshu Kumar, M., Bitla, A.R., Madhusudhana Rao, A. and Alok, S. (2013) Atherogenic Dyslipidemia in Diabetic Nephropathy: Lipoprotein (a), Lipid Ratios Atherogenic Index. International Journal of Research in Medical Sciences, 1 , 455-459. https://doi.org/10.5455/2320-6012.ijrms20131129

[15] Jisieike-Onuigbo, N.N., Unuigbe, E.I., Kalu, O.A., Oguejiofor, C.O. and Onuigbo, P.C. (2011) Prevalence of Dyslipidemia among Adult Diabetic Patients with Overt Diabetic Nephropathy in Anambra State South-East Nigeria. Nigerian Journal of Clinical Practice, 14, 171-175. https://doi.org/10.4103/1119-3077.84009

[16] Hoogeveen, R.C., Gaubatz, J.W., Sun, W., Dodge, R.C., Crosby, J.R., Jiang, J., et al. (2014) Small Dense Low-Density Lipoprotein-Cholesterol Concentrations Predict 
Risk for Coronary Heart Disease. Arteriosclerosis, Thrombosis, and Vascular Biology, 34, 1069-1077. https://doi.org/10.1161/ATVBAHA.114.303284

[17] Shoji, T., Hatsuda, S., Tsuchikura, S., Shinohara, K., Kimoto, E., Koyama, H., et al. (2009) Small Dense Low-Density Lipoprotein Cholesterol Concentration Carotid Atherosclerosis. Atherosclerosis, 202, 582-588.

https://doi.org/10.1016/j.atherosclerosis.2008.04.042

[18] Appel, G.B., Radhakrishnan, J., Avram, M.M., DeFronzo, R.A., Escobar-Jimenez, F., Campos, M.M., Burgess, E., Hille, D.A., Dickson, T.Z., Shahinfar, S. and Brenner, B.M. (2003) RENAAL Study. Analysis of Metabolic Parameters as Predictors of Risk in the RENAAL Study. Diabetes Care, 26, 1402-1407.

https://doi.org/10.2337/diacare.26.5.1402

[19] Shu, S., Wiebe, N., Fried, L.F. and Tonelli, M. (2006) Statins for Improving Renal Outcomes: A Meta-Analysis. Journal of the American Society of Nephrology, 17, 2006-2016. https://doi.org/10.1681/ASN.2006010012

[20] Contreras, G., Hu, B., Astor, B.C., Greene, T., Erlinger, T., Kusek, J.W., Lipkowitz, M., Lewis, J.A., Rall, O.S., Hebert, L., Wright Jr., J.T., Kendrick, C.A., Gassman, J., Bakris, G., Kopple, J.D. and Appel, L.J. (2010) African-American Study of Kidney Disease, Hypertension Study Group. Malnutrition-Inflammation Modifies the Relationship of Cholesterol with Cardiovascular Disease. Journal of the American Society of Nephrology, 21, 2131-2142. https://doi.org/10.1681/ASN.2009121285

[21] Chen, S.C., Hung, C.C., Tsai, Y.C., Huang, J.C., Kuo, M.C., Lee, J.J., Chiu, Y.W., Chang, J.M., Hwang, S.J. and Chen, H.C. (2013) Association of Cholesterol Levels with Mortality Cardiovascular Events among Patients with CKD Different Amounts of Proteinuria. The Clinical Journal of the American Society of Nephrology, 8, 1915-1926. https://doi.org/10.2215/CJN.02350213

[22] Wang, F., Zheng, J., Ye, P., Luo, L., Bai, Y., Xu, R., Sheng, L., Xiao, T. and Wu, H. (2013) Association of High-Density Lipoprotein Cholesterol with the Estimated Glomerular Filtration Rate in a Community-Based Population. PLoS ONE, 8, e79738. https://doi.org/10.1371/journal.pone.0079738

[23] Schaeffner, E.S., Kurth, T., Curhan, G.C., Glynn, R.J., Rexrode, K.M., Baigent, C., Buring, J.E. and Gaziano, J.M. (2003) Cholesterol the Risk of Renal Dysfunction in Apparently Healthy Men. Journal of the American Society of Nephrology,14, 2084-2091.

[24] Palazhy, S., et al. (2017) Lipid Abnormalities in Diabetic Nephropathy. Diabetes \& Metabolism Journal, 41, 128-134. http://e-dmj.org https://doi.org/10.4093/dmj.2017.41.2.128

[25] Misra, A. and Vikram, N.K. (2002) Insulin Resistance Syndrome (Metabolic Syndrome) Asian Indians. Current Science, 83, 1483-1496. 